\title{
Relationships and CPAP adherence among women with obstructive sleep apnea
}

\author{
Kelly Glazer Baron ${ }^{1 *}$, Heather E. Gunn², Lisa F. Wolfe ${ }^{3}$ and Phyllis C. Zee ${ }^{3}$
}

\begin{abstract}
Background: Obstructive sleep apnea contributes to daytime sleepiness, poor quality of life and increased risk for heart disease and hypertension among women. Continuous positive airway pressure improves sleepiness and quality of life and may reduce health risks but few studies have evaluated predictors of adherence among women. The goal of this study was to evaluate the role of relationship factors in women's continuous positive airway pressure (CPAP) adherence and change in relationship quality among married/partnered women.

Methods: Women recently diagnosed with obstructive sleep apnea completed relationship quality, social support questionnaires and spousal involvement interviews. CPAP adherence was collected at 12 weeks.

Results: Data were available for 16 women. Average CPAP adherence was $3.6 \mathrm{SD}=2.7 \mathrm{~h}$ per night. Women with higher reports of social support had higher adherence. None of the unmarried/partnered participants were adherent to the recommendation of CPAP use $\geq 4 \mathrm{~h}$ per night at 12 week follow-up. Marital status was not associated with demographic, disease severity or social support measures. Relationship conflict among married/partnered participants was associated with lower adherence. In qualitative surveys, encouragement and support were the two most commonly reported types of partner involvement. Relationship quality did not change between baseline and 3 months.
\end{abstract}

Conclusion: Results suggest relationship factors are robust predictors of CPAP adherence among women with obstructive sleep apnea.

Keywords: Obstructive apnea, Continuous positive airway pressure, Adherence

\section{Background}

Obstructive sleep apnea (OSA) prevalence rapidly increases among middle aged women, and prevalence of moderate to severe OSA is $6 \%$ of postmenopausal women (Redline et al. 2014). Consequences of OSA include daytime sleepiness, depressive symptoms, decreased quality of life as well as increased risk for cardiovascular disease, diabetes and stroke (Doherty et al. 2005; Engleman et al. 1994; Marin et al. 2005, 2012). The main treatment for OSA is continuous positive airway pressure (CPAP), in which the patient wears a mask connected to a small machine that pushes humidified air into the airway, thus preventing airway collapse during sleep. Despite the benefits of continuous positive airway pressure (CPAP) for health and quality of life, $46-83 \%$ of OSA patients are non-adherent (Weaver

\footnotetext{
* Correspondence: kgbaron@rush.edu

'Department of Behavioral Sciences, Rush University Medical Center, 1653 W. Congress Parkway, Chicago, IL 60612-3833, USA

Full list of author information is available at the end of the article
}

and Grunstein 2008). Understanding women's CPAP use is important because women with untreated OSA have increased risk of hypertension, stroke and cardiovascular death. Two studies have highlighted elevated cardiovascular mortality and stroke in samples of women with OSA (Campos-Rodriguez et al. 2012, 2014). Few studies have focused on women with OSA and only a handful of those examine CPAP adherence (Ye et al. 2009). Three studies have demonstrated that women have poorer adherence compared to men (Joo and Herdegen 2007; Pelletier-Fleury et al. 2001; Woehrle et al. 2011). In an urban public hospital, for example, women were 1.72 times more likely to be non-adherent to CPAP even when adjusting for age and race (Joo and Herdegen 2007). However, one study reported higher adherence in women (Sin et al. 2002) and two studies have reported no relationship between gender and adherence (Gagnadoux et al. 2011; McArdle et al. 1999). 
Given that so few studies have explored effects of gender in adherence rates, even fewer studies have explored the role of gender in CPAP adherence. Relationship quality is a factor known to affect adherence to many different medical treatments, such as medication and dialysis adherence (DiMatteo 2004; Gove et al. 1990; Lewis and Butterfield 2007). However few studies have evaluated the role of social support and relationship quality in CPAP and none have been conducted among female patients. Despite compelling evidence linking relationships and social support to health (Uchino 2006; House et al. 1988; Walen and Lachman 2000), there is limited understanding of the role of relationships in CPAP treatment, especially among women. One study conducted in men and women found that having a bed partner was associated with greater CPAP adherence (Lewis et al. 2004). A recent study found that being married was associated with higher adherence in a sample of both women and men (Gagnadoux et al. 2011). However, these studies did not take into account relationship quality or they ways in which spouses were involved. We previously reported in a study of male patients with OSA, higher relationship conflict was associated with poorer adherence and collaborative spousal involvement by the spouse was associated with greater CPAP adherence (Baron et al. 2011; Baron KG 2008). Given that women are more physically and emotionally reactive to relationship conflict (Kiecolt-Glaser and Newton 2001) and both marital status and relationship quality have been associated with women's sleep quality (Gallo et al. 2003).

Therefore, the purpose of this study was to evaluate the role of relationship status and relationship quality in CPAP adherence among women with newly diagnosed OSA. We predicted that being married or partnered, as well as having higher relationship quality and higher general levels of social support would be associated with higher adherence. Our battery included known predictors of CPAP adherence (self-efficacy for CPAP), presleep arousal, which has been related to relationship quality, and a measure of insomnia symptoms, which are more common among women. We also assessed partner support through open-ended questions with married or partnered participants to explore the helpful and unhelpful ways their partners were involved in CPAP treatment. Finally, we evaluated change in relationship quality among married/partnered participants over the first 3 months of starting CPAP.

\section{Methods}

\section{Participants}

This study was approved by the Northwestern University Institutional Review Board and all participants completed written informed consent. Women who were undergoing polysomnography due to suspected OSA were recruited for the study from the Northwestern Medical Center Sleep Disorders Laboratory. Patients were recruited at the diagnostic, split night or titration study and completed questionnaires before CPAP was set up at home. Inclusion criteria included: female gender and CPAP naïve. Exclusionary criteria included: diagnosis of chronic obstructive pulmonary disease, neurological disorders, use of supplemental oxygen, plan to undergo surgery in the next 3 months, use of other treatments for OSA (including bariatric surgery, upper airway surgery, or oral appliance), dementia, inability to read or write in English and unstable psychiatric disorders.

\section{Procedure}

Female participants undergoing diagnostic, split night, or CPAP titration studies aged 18-70 were recruited using flyers and phone calls. Participants who were interested in the study were invited to complete questionnaires in a one hour visit to the sleep research laboratory. Pre-treatment questionnaires were scheduled after an OSA diagnosis was confirmed via polysomnography but before CPAP was set up in their home. All PSG were conducted in the laboratory (no home PSG studies) and were scored using standard AASM criteria. Patients participated in the standard clinic protocol for titration and CPAP initiation. All participants had mask fittings and CPAP education with a sleep technician at the titration or split night study. Patients were assigned to durable medical equipment (DME) companies for CPAP set-up per the clinic's usual practices. The DME company representative again reviewed the use and care of the equipment as well as the importance of compliance. CPAP machine settings were determined by the ordering physician who was blinded to study enrollment status of each patient. Adherence was determined objectively, based on reports generated by querying the internal recording system that accompanies the CPAP devices. The data was obtained by electronic download at 10-12 weeks after treatment initiation.

\section{Measures}

Demographics: Age, gender, race, education, and income were assessed by self-report.

Depressive Symptoms: Depressive symptoms were assessed using the Center for Epidemiologic Studies Depression Scale, (CES-D; Radloff 1977). This 20-item measure is a commonly used and well-validated measure of depressive symptoms in which scores $\geq 16$ are associated with clinically elevated depressive symptoms in middle-aged and older adults.

Subjective Sleepiness: The Epworth Sleepiness Scale (ESS) was used to assess self-reported subjective sleepiness at baseline (Johns 1991). In this questionnaire, participants rate the likelihood they would fall asleep in 8 
different situations, such as being a passenger in a car. Scores range from $0-24$ and scores $>10$ have been associated with excessive sleepiness (Johns 1991).

Relationship Quality: Relationship quality was measured by the Quality of Relationship Inventory (QRI) support and conflict subscales at baseline and follow-up (Pierce et al. 1991). The support subscale contained items related to emotional support in the marriage, such as "To what extent could you count on your spouse for help with a problem?" and "To what extent could you count on this person to listen to you when you are very angry at someone else?" The conflict subscale contained items related to the frequency and extent of marital conflict, such as, "How angry does your spouse make you feel?" and "How often do you have to work hard to avoid conflict with your spouse?" Subscales were scored as the average of the 7 support items and average of the 12 conflict items. Reported test-retest reliability correlations ranged from 0.48 to 0.79 (Pierce et al. 1997; Verhofstadt et al. 2006). This questionnaire in our sample demonstrated adequate internal consistency (Cronbach's alpha = 0.80 for the support subscale and 0.74 for the conflict subscale).

Social Support: Social support was measured using the Enhancing Recovery in Coronary Heart Disease Patients social support index (ESSI) (Mitchell et al. 2003). This 8 item questionnaire measures structural, instrumental, and emotional social support. Scores range from 8 to 34, with higher scores indicating greater social support. This measure had good internal consistency in our sample (Cronbach's alpha = 0.86). Although it was developed in cardiac patients, this measure has been used in other medical populations including cancer and HIV (Penedo et al. 2012; Mergenova et al. 2016).

Sleep Apnea Self-Efficacy: Self efficacy related to sleep apnea was measured by the Self Efficacy Measure for Sleep Apnea. This 26-item measure contains 3 subscales: risk perception of OSA (e.g., "chances of falling asleep driving"), outcome expectancies of CPAP (e.g., "job performance will improve"), and treatment self-efficacy (e.g., "I would use CPAP if it made my nose stuffy"). Patients completed this measure at baseline. In validation studies of OSA patients, this scale demonstrated good psychometric properties. Cronbach's alpha was reported as 0.90 for the total scale, $0.85-0.89$ for the 3 subscales and reported test-retest reliabilities ranged from 0.68-0.77 (Weaver et al. 2003). In our sample, Cronbach's alpha was between 0.70 and 0.89 .

Perceived important of OSA treatment: We assessed perceived importance for OSA treatment in one item: "How important is it to you that you are treated for OSA". Item responses range from 0 (not at all) to 5 (very motivated).
Pre-sleep Arousal was measured by the Pre-sleep arousal scale (Nicassio et al. 1985). This 16 item scale has two subscales "cognitive" and "somatic". Items for the cognitive arousal subscale include the feeling of having an active mind before sleep, anxious or depressed thoughts. The somatic pre-sleep arousal subscale includes physical feelings of anxiety and restlessness before sleep, such as a racing heart. Items are scored from 1 (not at all) to 4 (extremely). Scores range from 8-40. This scale has demonstrated adequate reliability and internal validity (Nicassio et al. 1985; Jansson-Frojmark and Norell-Clarke 2012).

Insomnia Symptoms were measured by the Insomnia Severity Index (ISI). This 5 item scale assesses symptoms of insomnia as well as satisfaction with quality of sleep and concern about the impact of sleep on quality of life (Morin 1993). Chronbach's alpha demonstrated adequate internal consistency (0.74) and this measure has been demonstrated to have adequate concurrent validity and sensitivity to improvements in sleep (Bastien et al. 2001).

Apnea severity was determined by the apnea severity index (apnea or hypopnea events per hour) on the diagnostic polysomnography or the diagnostic portion of the split night polysomnogram.

\section{Data analysis}

Data were analyzed using SPSS Version 20. Participant characteristics were described using means, standard deviations, and percentages. Associations between relationship status, quality, and CPAP adherence were evaluated using Pearson correlations and linear regression. All tests were 2-tailed and statistical significance was defined as $p<0.05$.

\section{Results}

\section{Sample characteristics}

Sample characteristics are listed in Table 1. During the recruitment period, 384 women underwent polysomnography and study staff identified 129 women who met eligibility criteria for the study. Reasons for nonparticipation were not provided by most of the potential participants but those who did provide reasons reported: they were not starting CPAP $(n=6)$, they did not have time to participate $(n=3)$ and they already started CPAP at home $(n=4)$. Of the eligible women who were provided flyers and phone calls, 33 women volunteered for the study. Nine women dropped out without providing a reason before completing informed consent. A total of 24 women provided informed consent and completed baseline questionnaires for the study. There were no differences in age, BMI, insurance type, AHI between participants and non-participants. After enrollment, three participants declined CPAP treatment and data from one participant was removed from the analyses due to 
Table 1 Participant Characteristics

\begin{tabular}{ll}
\hline$N=20$ & M (SD) or N (\%) \\
\hline Age & $50(10)$ years \\
Race/Ethnicity & $6(30 \%)$ \\
Black & $9(45 \%)$ \\
White & $4(20 \%)$ \\
Latina & $1(5 \%)$ \\
Other/more than one race & \\
Marital Status & $7(35 \%)$ \\
Married & $6(30 \%)$ \\
Living with a romantic partner & $5(25 \%)$ \\
Never married, living alone & $2(10 \%)$ \\
Other (separated, widowed) & $20.5(16.3)$ events/h \\
Apnea Hypopnea Index & $11.7(5.0)$ \\
Epworth Sleepiness Scale & $37.8(10.8) \mathrm{kg} / \mathrm{m}^{2}$ \\
Body Mass Index & \\
CPAP Adherence & \\
Average use per night & $3.7(2.8)$ hours \\
Percentage with adherence $\geq 4 \mathrm{~h}, 70 \%$ of nights & 6 of 16 (38\%) \\
\hline aCPAP adherence data were missing for 4 participants (unable to contact 3 \\
participants, equipment failure in 1 participant)
\end{tabular}

prior CPAP use. Therefore, the resulting sample was 20 participants (with adherence data available for 16 of the 20 participants). Missing adherence data were due to inability to contact participant for download $(n=3)$ and one participant did not have a chip to record adherence. The sample was $45 \%(n=6)$ non-Hispanic white. Over half of participants were married or living with a romantic partner $(n=13,65 \%)$. There was a range of apnea severity but the average AHI was in the moderate range. Average subjective sleepiness was $>10$ and BMI was in the obese range. Average adherence was $3.7 \mathrm{~h}(\mathrm{SD}=2.8)$ and the range was $0.1 \mathrm{~h}$ to $7.8 \mathrm{~h}$. Of the 16 participants with adherence data, 6 (38\%) were considered adherent (CPAP $\geq 4$ h on $\geq 70 \%$ of nights).

\section{Associations with CPAP Adherence}

Comparisons of characteristics of married/partnered vs. unmarried partnered participants are listed in Table 2 . There was a trend for higher average nightly CPAP use among married/partnered participants compared to unmarried/unpartnered participants ( $4.6 \mathrm{~h}$ versus $2.1 \mathrm{~h}, p<$ $0.08)$. Using the Medicare adherence criteria of $\geq 4 \mathrm{~h}$ of use on $70 \%$ of nights, $40 \%$ of married or partnered participant and $100 \%$ of the unpartnered patients were nonadherent $(p<.05)$. Unmarried/unpartnered participants reported greater CPAP self-efficacy $(p<.05)$ but there were no other differences demographic, disease related, or psychosocial characteristics between married/partnered and unpartnered participants.
Table 2 Comparison of key variables for married/partnered versus unmarried/unpartnered participants

\begin{tabular}{|c|c|c|}
\hline & $\begin{array}{l}\text { Married or partnered } \\
\text { women }(N=13) \\
M(S D) \text { or } N(\%)\end{array}$ & $\begin{array}{l}\text { Unmarried and } \\
\text { unpartnered } \\
\text { women }(N=7) \\
\text { M (SD) or } N(\%)\end{array}$ \\
\hline Age & $50.8(9.1)$ & $48.7(12.0)$ \\
\hline \multicolumn{3}{|l|}{ Race } \\
\hline White & $7(53)$ & $2(29)$ \\
\hline Black & $3(23)$ & $3(43)$ \\
\hline Hispanic/Latina & $5(15)$ & $2(29)$ \\
\hline Other/More than 1 race & $1(8)$ & $0(0)$ \\
\hline Apnea Hypopnea Index & $16.2(12.4)$ & $28.4(20.5)$ \\
\hline Epworth Sleepiness Scale & $11.7(4.7)$ & $11.7(5.9)$ \\
\hline Body Mass Index & $35.0(8.4)$ & $42.7(13.4)$ \\
\hline Split night study & $4(57)$ & $3(23)$ \\
\hline \multicolumn{3}{|l|}{ CPAP Adherence* } \\
\hline Average use per night & $4.6(2.8)$ & $2.1(1.7)^{\dagger}$ \\
\hline $\begin{array}{l}\text { Adherence } \geq 4 \text { h, } 70 \% \\
\text { of nights }\end{array}$ & $6(60)$ & $0(0)^{*}$ \\
\hline $\begin{array}{l}\text { Center for Epidemiologic } \\
\text { Depression Scale (CES-D) }\end{array}$ & $12.9(6.6)$ & $13.9(4.3)$ \\
\hline CPAP Self-Efficacy & $27.4(6.7)$ & $34.6(4.6)^{*}$ \\
\hline $\begin{array}{l}\text { Perceived importance of } \\
\text { treating OSA (1, not } \\
\text { important-5, very important) }\end{array}$ & $4.7(0.9)$ & $4.9(0.4)$ \\
\hline Insomnia Severity Index & $15.5(7.9)$ & $20.4(6.6)$ \\
\hline \multicolumn{3}{|l|}{ Presleep Arousal Scale } \\
\hline Cognitive & $20.9(10.2)$ & $23.9(9.4)$ \\
\hline Somatic & $16.5(9.5)$ & $19.5(9.4)$ \\
\hline
\end{tabular}

Correlations between adherence, relationship quality, social support, self-efficacy, and pre-sleep arousal are listed in Table 3. Among married or partnered patients, relationship conflict was negatively associated with adherence $(r=-0.60, p<0.05$, Fig. 1). Ratings of support in the relationship were unassociated with adherence. Greater perceived social support was positively associated with adherence among all participants $(r=0.65, p<0.05$, Fig. 2). In addition, both cognitive and somatic pre-sleep arousal were associated with poorer CPAP adherence $(r=-0.53, p<0.05$, $r=-0.59, p<0.05$, $)$ and higher relationship conflict $(r$ $=0.66, p<0.05, r=0.53, p<0.05)$. Depressive symptoms were correlated with relationship conflict $(r=$ $0.58, p<0.05)$, social support $(r=-0.48, p<0.05)$, cognitive $(r=0.60, p<0.05)$ and somatic pre-sleep arousal $(r=$ $0.63, p<0.05)$. Relationship support, depressive symptoms, insomnia symptoms, CPAP self- efficacy were not associated with CPAP adherence. 
Table 3 Correlations between CPAP use, relationship quality and social support

\begin{tabular}{|c|c|c|c|c|c|c|c|c|c|}
\hline & 1. & 2. & 3. & 4. & 5. & 6. & 7. & 8. & 9. \\
\hline 1. CPAP Use & - & $-.60^{*}$ & .37 & $.65^{*}$ & .30 & .01 & .01 & $-.53^{*}$ & $-.59^{*}$ \\
\hline 2. Relationship conflict & & - & -.25 & -.47 & -.33 & -.01 & .31 & $.66^{* *}$ & $.53^{*}$ \\
\hline 3. Relationship support & & & - & .09 & -.02 & -.13 & -.34 & -.41 & -.46 \\
\hline 4. Social support & & & & - & -.14 & .09 & -.06 & -.36 & -.39 \\
\hline 5. OSA risk & & & & & - & .28 & -.23 & -.13 & -.06 \\
\hline 6. CPAP expectations & & & & & & - & .04 & .23 & .48 \\
\hline 7. OSA self-efficacy & & & & & & & - & .21 & .11 \\
\hline 8. Cognitive pre-sleep arousal & & & & & & & & - & .74 \\
\hline 9. Physiological pre-sleep arousal & & & & & & & & & - \\
\hline
\end{tabular}

\section{Qualitative responses about "helpful" and "unhelpful" spousal behaviors}

One week after CPAP initiation, 7 participants provided responses to open ended questions about helpful and unhelpful ways their spouse or partner was involved in CPAP. The majority (6 of 7) of participants reported support and encouragement from their spouse/partner to use CPAP. Helpful types of involvement reported by participants included: asking about CPAP, problem solving, support, providing encouragement, using humor, helping the participant "realize the benefits" of CPAP, encouraging use to "better my health", helping the participant to feel less selfconscious about it, and checking to see if she is snoring at night. One participant reported her spouse was not involved in CPAP use and two participants report unhelpful types of involvement. Unhelpful types of involvement listed included: repeatedly asking if "it's working" and making fun of the participant (referring to it as a "Darth Vader" mask).

\section{Change in relationship quality}

Participants did not demonstrate changes in overall relationship quality, relationship support or conflict (Table 4).

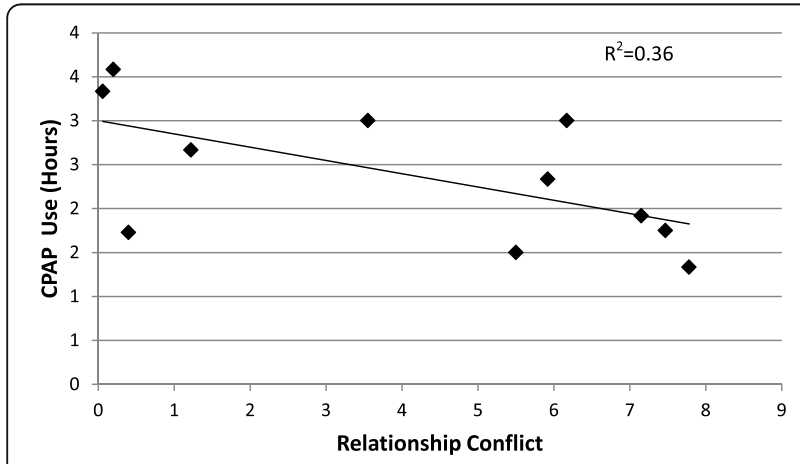

Fig. 1 Relationship conflict is associated with lower CPAP use

\section{Discussion}

Results of this study demonstrate that both relationship status and relationship quality strongly predict women's CPAP adherence. We found a very strong link between relationship status (being married or living with a partner) and adherence, in that $40 \%$ of married/partnered participants were adherent according to the criteria set by Medicare whereas none of the unpartnered participants were adherent ( $\geq 4 \mathrm{~h}$ of CPAP use on $70 \%$ of nights). Furthermore, there was a strong correlation between ratings of conflict in the relationship (for married/partnered patients) as well as general levels of social support and CPAP adherence. Therefore, even in the case of unpartnered participants, higher levels of support from other sources was associated with better adherence.

In an attempt to explain the effects of relationship status on CPAP, we explored differences in demographic, physical, and psychological variables. CPAP self-efficacy was actually higher among unmarried/unpartnered participants. However, we did find associations between relationship quality and social support variables with depression and pre-sleep arousal. Although our sample size is too small to formally explore a mediation pathway, this may be one way relationship conflict interferes with CPAP adherence among women. Both cognitive

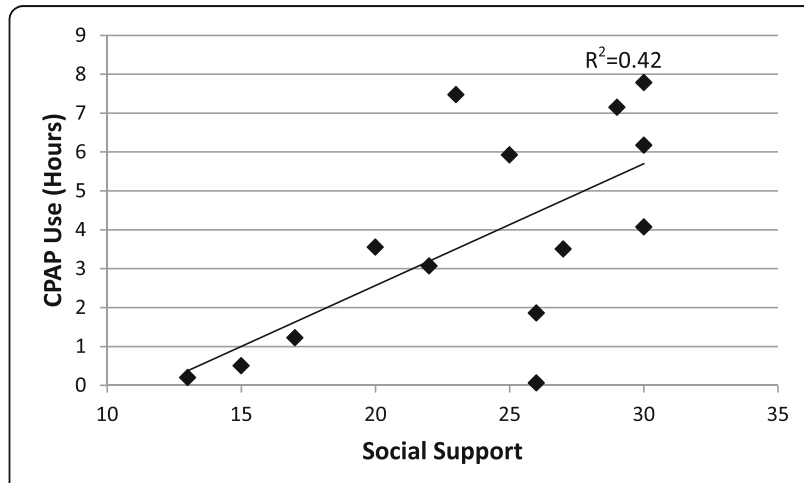

Fig. 2 Social support is associated with higher CPAP use 
Table 4 Relationship quality measures at baseline and 3 month follow-up for married/partnered participants $(N=13)$

\begin{tabular}{lll}
\hline & Baseline & 3 Month follow-up \\
\hline Relationship quality total score & $60.3(11.3)$ & $59.7(10.4)$ \\
Relationship support & $3.5(0.5)$ & $3.4(0.8)$ \\
Relationship conflict & $2.0(0.7)$ & $2.1(0.7)$ \\
\hline
\end{tabular}

$P$ values are all non-significant

(e.g., active thoughts and worry) as well as somatic presleep arousal (e.g., physical tension) were associated with poorer CPAP use. Poor marital quality may increase presleep arousal, which may in turn negatively impact CPAP adherence. Because patients wear CPAP at bedtime, marital stress and lack of support may hinder women's motivation to use CPAP because they may be more preoccupied with other factors, such as managing relationship stress. It is also possible the feeling "wound up" cognitively or physiologically may interfere with the ability to tolerate CPAP in women. Previous studies have found that marital happiness is associated with better sleep quality in women, above and beyond depression (Troxel et al. 2007).

We also queried married/partnered participants about what they found to be helpful and unhelpful behaviors from their spouse or partner one week after starting CPAP. The majority reported that support and encouragement from their partner was an important factor in their CPAP adherence. In addition, patients reported their partners were involved in many different ways, including helping them feel less self-conscious and helping solve problems and check that they are wearing the CPAP properly (e.g., monitoring for snoring). All but one of the patients who responded to the open ended questions could generate examples of helpful spousal involvement. We received fewer answers on the item about unhelpful spousal involvement. It is possible that the women who did not provide responses to this question either did not experience unhelpful spousal involvement or were reluctant to report it. Our previous study of spousal involvement in men utilized a written survey and found that $57 \%$ of male patients reported their spouse attempted to scare them into using CPAP, which is typically viewed as a negative tactic (Baron et al. 2011).

Results of our study add to a broader context of the role of relationships in OSA and CPAP use as well as the role of gender in OSA treatment. The symptoms of OSA, including snoring, daytime sleepiness, and depressed mood, affect both patient and partner quality of life (Doherty et al. 2003; Reishtein et al. 2006; Cartwright 2008; Cartwright and Knight 1987; Baron et al. 2009). In male participants, relationship conflict was associated with poorer adherence and collaborative involvement from the spouse was associated with higher adherence (Baron et al. 2009, 2011). Results of this study cannot address gender differences per se; but, we can compare magnitude of correlations between studies. In our previously published study in men, the correlation between relationship conflict and adherence was -0.31 whereas in this current study in women, it is twice as strong $(-0.61)$. Although relationship conflict may be deleterious for CPAP adherence in both men and women, it may have a greater negative impact on women's CPAP use. In addition, we reported a decrease in perceived relationship conflict among men who started CPAP, whereas in this study we did not observe a change in relationship measures among women.

Our results are limited by a small sample size and recruitment from a single center. It is possible we were unable to observe associations with adherence among some of the typical predictors (e.g., self-efficacy) due to low statistical power from samples size and/or lack of variability in the measures. This study was also unable to identify the frequency of symptoms such as claustrophobia, which may have affected adherence. Strengths of this study are in-depth assessment of spousal involvement and diversity of the sample in terms of age, race/ethnicity, and social structure. Future studies conducted in larger samples may elucidate the pathways between these interrelated variables, and inform the design of interventions that take into account relationship factors. Our results suggest that increasing helpful spousal involvement may be helpful for both men and women. We previously reported that collaborative involvement and support were associated with higher adherence (Baron et al. 2011, 2012). To date only one intervention has specifically involved spouses (Hoy et al. 1999) and found that increasing helpful involvement was one part of a successful intervention.

\section{Conclusions}

These data suggest that the context of a supportive relationship is highly important to women's CPAP use. Understanding of gender and social processes among women with OSA expands our knowledge and ability to modify risk factors for poor CPAP adherence in this population.

\section{Acknowledgements \\ We gratefully acknowledge the contributions of Erin McGorry, Brittany Fondel and Nirmit Desai for their assistance with data collection and data entry.}

\section{Funding}

This work was supported by the National Institutes of Health grants 1K23HL10911001 and $5 \mathrm{~K} 12 \mathrm{HD} 055884$. The funding agencies were not involved in the design, data collection, analysis or interpretation of the manuscript.

\section{Availability of data and materials}

The datasets used during the current study are not currently available to the public due to the small sample, which may pose a threat for confidentiality, but the authors are willing to make the data available on reasonable request by contacting the corresponding author. 


\section{Authors' contributions}

KGB contributed to study design, data collection, data analysis and was the main author involved in writing the manuscript. HEG contributed to data collection and writing the manuscript. LFW and PCZ contributed to study design, interpretation of results and writing the manuscript. All authors read and approved the final manuscript.

\section{Competing interests}

The authors declare that they have no competing interests.

\section{Consent for publication}

N/A

\section{Ethics approval and consent to participate}

This study was approved by the Institutional Review Board at Northwestern University and all participants completed written informed consent documents.

\section{Publisher's Note}

Springer Nature remains neutral with regard to jurisdictional claims in published maps and institutional affiliations.

\section{Author details}

'Department of Behavioral Sciences, Rush University Medical Center, 1653 W. Congress Parkway, Chicago, IL 60612-3833, USA. 'Department of Psychiatry, University of Pittsburgh, Pittsburgh, USA. ${ }^{3}$ Center for Circadian and Sleep Medicine, Feinberg School of Medicine, Northwestern University, Chicago, USA.

Received: 4 January 2017 Accepted: 8 March 2017

Published online: 24 May 2017

\section{References}

Baron KG. Effects of relationship quality and social control on adherence to CPAP in patients with obstructive sleep apnea. Dissertation Abstracts International: Section B: The Sciences and Engineering. 2008. p. 68.

Baron KG, Smith TW, Czajkowski LA, Gunn HE, Jones CR. Relationship quality and CPAP adherence in patients with obstructive sleep apnea. Behav Sleep Med. 2009; $7: 22-36$

Baron KG, Smith TW, Berg CA, Czajkowski LA, Gunn H, Jones CR. Spousal involvement in CPAP adherence among patients with obstructive sleep apnea. Sleep Breath. 2011;15:525-34.

Baron KG, Gunn HE, Czajkowski LA, Smith TW, Jones CR. Spousal involvement in CPAP: does pressure help? Clin Sleep Med. 2012;8:147-53.

Bastien $\mathrm{CH}$, Vallieres A, Morin CM. Validation of the insomnia severity index as an outcome measure for insomnia research. Sleep Med. 2001;2:297-307.

Campos-Rodriguez F, Martinez-Garcia MA, de la Cruz-Moron I, Almeida-Gonzalez C, Catalan-Serra P, Montserrat JM. Cardiovascular mortality in women with obstructive sleep apnea with or without continuous positive airway pressure treatment: a cohort study. Ann Intern Med. 2012;156:115-22.

Campos-Rodriguez F, Martinez-Garcia MA, Reyes-Nunez N, Caballero-Martinez I, Catalan-Serra P, Almeida-Gonzalez CV. Role of sleep apnea and continuous positive airway pressure therapy in the incidence of stroke or coronary heart disease in women. Am J Respir Crit Care Med. 2014;189:1544-50.

Cartwright RD. Sleeping together: a pilot study of the effects of shared sleeping on adherence to CPAP treatment in obstructive sleep apnea. J Clin Sleep Med. 2008;4:123-7.

Cartwright RD, Knight S. Silent partners: the wives of sleep apneic patients. Sleep. 1987;10:244-8.

DiMatteo MR. Social support and patient adherence to medical treatment: a meta-analysis. Health Psychol. 2004;23:207-18.

Doherty LS, Kiely JL, Lawless G, McNicholas WT. Impact of nasal continuous positive airway pressure therapy on the quality of life of bed partners of patients with obstructive sleep apnea syndrome. Chest. 2003;124:2209-14.

Doherty LS, Kiely JL, Swan V, McNicholas WT. Long-term effects of nasal continuous positive airway pressure therapy on cardiovascular outcomes in sleep apnea syndrome. Chest. 2005;127:2076-84.

Engleman HM, Martin SE, Deary IJ, Douglas NJ. Effect of continuous positive airway pressure treatment on daytime function in sleep apnoea/hypopnoea syndrome. Lancet. 1994;343:572-5.

Gagnadoux F, Le Vaillant M, Goupil F, Pigeanne T, Chollet S, Masson P, Humeau MP, Bizieux-Thaminy A, Meslier N. Influence of marital status and employment status on long-term adherence with continuous positive airway pressure in sleep apnea patients. PLoS ONE. 2011;6:e22503.

Gallo LC, Troxel WM, Matthews KA, Kuller LH. Marital status and quality in middleaged women: Associations with levels and trajectories of cardiovascular risk factors. Health Psychol. 2003;22:453-63.

Gove WR, Style CB, Hughes M. The effect of marriage on the well-being of adults: a theoretical analysis. J Fam Issues. 1990;11:4-35.

House JS, Landis KR, Umberson D. Social relationships and health. Science. 1988; 241:540-5.

Hoy CJ, Vennelle M, Kingshott RN, Engleman HM, Douglas NJ. Can intensive support improve continuous positive airway pressure use in patients with the sleep apnea/hypopnea syndrome? Am J Respir Crit Care Med. 1999;159: 1096-100.

Jansson-Frojmark M, Norell-Clarke A. Psychometric properties of the pre-sleep arousal scale in a large community sample. J Psychosom Res. 2012;72:103-10.

Johns MW. A new method for measuring daytime sleepiness: the Epworth sleepiness scale. Sleep. 1991;14:540-5.

Joo MJ, Herdegen JJ. Sleep apnea in an urban public hospital: assessment of severity and treatment adherence. J Clin Sleep Med. 2007;3:285-8.

Kiecolt-Glaser JK, Newton TL. Marriage and health: his and hers. Psychol Bull. 2001;127:472-503.

Lewis MA, Butterfield RM. Social control in marital relationships: effect of one's partner on health behaviors. J Appl Soc Psychol. 2007;37:298-319.

Lewis KE, Seale L, Bartle IE, Watkins AJ, Ebden P. Early predictors of CPAP use for the treatment of obstructive sleep apnea. Sleep. 2004;27:134-8.

Marin JM, Carrizo SJ, Vicente E, Agusti AG. Long-term cardiovascular outcomes in men with obstructive sleep apnoea-hypopnoea with or without treatment with continuous positive airway pressure: an observational study. Lancet. 2005;365:1046-53.

Marin JM, Agusti A, Villar I, Forner M, Nieto D, Carrizo SJ, Barbe F, Vicente E, We Y, Nieto FJ, Jelic S. Association between treated and untreated obstructive sleep apnea and risk of hypertension. JAMA. 2012;307:2169-76.

McArdle N, Devereux G, Heidarnejad H, Engleman HM, Mackay TW, Douglas NJ. Long-term use of CPAP therapy for sleep apnea/hypopnea syndrome. Am J Respir Crit Care Med. 1999;159:1108-14.

Mergenova G, Shaw SA, Terlikbayeva A, Gilbert L, Gensburg L, Primbetova S, ElBassel N. social support and HIV risks among migrant and non-migrant market workers in Almaty, Kazakhstan. J Immigr Minor Health. 2016.

Mitchell PH, Powell L, Blumenthal J, Norten J, Ironson G, Pitula CR, Froelicher ES, Czajkowski S, Youngblood M, Huber M, Berkman LF. A short social support measure for patients recovering from myocardial infarction: the ENRICHD social support inventory. J Cardiopulm Rehabil. 2003;23:398-403.

Morin CM. Insomnia: psychological assessment and management. New York: Guilford Press; 1993.

Nicassio PM, Mendlowitz DR, Fussell JJ, Petras L. The phenomenology of the presleep state: the development of the pre-sleep arousal scale. Behav Res Ther. 1985;23:263-71.

Pelletier-Fleury N, Rakotonanahary D, Fleury B. The age and other factors in the evaluation of compliance with nasal continuous positive airway pressure for obstructive sleep apnea syndrome. A Cox's proportional hazard analysis. Sleep Med. 2001;2:225-32.

Penedo FJ, Traeger L, Benedict C, Thomas G, Dahn JR, Krause MH, Goodwin WJ. Perceived social support as a predictor of disease-specific quality of life in head-and-neck cancer patients. J Support Oncol. 2012;10:119-23.

Pierce GR, Sarason IG, Sarason BR. General and relationship-based perceptions of social support: are two constructs better than one? J Pers Soc Psychol. 1991; 61:1028-39.

Pierce GR, Sarason IG, Sarason BR, Solky-Butzel JA, Nagel LC. Assessing the quality of personal relationships. J Soc Pers Relat. 1997;14:339-56.

Radloff LS. The CES-D scale: a self-report depression scale for research in the general population. Appl Psychol Meas. 1977;1:385-401.

Redline S, Sotres-Alvarez D, Loredo J, Hall M, Patel SR, Ramos A, Shah N, Ries A, Arens R, Barnhart J, et al. Sleep-disordered breathing in hispanic/latino individuals of diverse backgrounds. The hispanic community health study/ study of Latinos. Am J Respir Crit Care Med. 2014;189:335-44.

Reishtein JL, Pack Al, Maislin G, Dinges DF, Bloxham TJ, George CF, Greenberg H, Kader GA, Mahowald MW, Younger JB, Weaver TE. Sleepiness and relationships in obstructive sleep apnea. Issues Ment Health Nurs. 2006;27:319-30.

Sin DD, Mayers I, Man GC, Pawluk L. Long-term compliance rates to continuous positive airway pressure in obstructive sleep apnea: a population-based study. Chest. 2002;121:430-5. 
Troxel WM, Robles TF, Hall M, Buysse DJ. Marital quality and the marital bed: examining the covariation between relationship quality and sleep. Sleep Med Rev. 2007;11:389-404.

Uchino BN. Social support and health: a review of physiological processes potentially underlying links to disease outcomes. J Behav Med. 2006;29:377-87.

Verhofstadt LL, Buysse A, Rosseel Y, Peene OJ. Confirming the three-factor structure of the quality of relationships inventory within couples. Psychol Assess. 2006;18:15-21.

Walen HR, Lachman ME. Social support and strain from partner, family, and friends: costs and benefits for men and women in adulthood. J Soc Pers Relat. 2000;17(1):5-30.

Weaver TE, Grunstein RR. Adherence to continuous positive airway pressure therapy: the challenge to effective treatment. Proc Am Thorac Soc. 2008;5: 173-8.

Weaver TE, Maislin G, Dinges DF, Younger J, Cantor C, McCloskey S, Pack Al. Selfefficacy in sleep apnea: instrument development and patient perceptions of obstructive sleep apnea risk, treatment benefit, and volition to use continuous positive airway pressure. Sleep. 2003;26:727-32.

Woehrle H, Graml A, Weinreich G. Age- and gender-dependent adherence with continuous positive airway pressure therapy. Sleep Med. 2011;12:1034-6.

Ye LC, Pien GW, Weaver TE. Gender differences in the clinical manifestation of obstructive sleep apnea. Sleep Med. 2009:10:1075-84.

\section{Submit your next manuscript to BioMed Central} and we will help you at every step:

- We accept pre-submission inquiries

- Our selector tool helps you to find the most relevant journal

- We provide round the clock customer support

- Convenient online submission

- Thorough peer review

- Inclusion in PubMed and all major indexing services

- Maximum visibility for your research

Submit your manuscript at www.biomedcentral.com/submit 